Review Article

\title{
Vasopressin in Hemorrhagic Shock: A Systematic Review and Meta-Analysis of Randomized Animal Trials
}

\author{
Andrea Pasquale Cossu, ${ }^{1}$ Paolo Mura, ${ }^{1}$ Lorenzo Matteo De Giudici, ${ }^{1}$ \\ Daniela Puddu, ${ }^{1}$ Laura Pasin, ${ }^{2}$ Maurizio Evangelista, ${ }^{3}$ Theodoros Xanthos, ${ }^{4}$ \\ Mario Musu, ${ }^{1}$ and Gabriele Finco ${ }^{1}$ \\ ${ }^{1}$ Department of Medical Sciences "M. Aresu”, University of Cagliari, SS.554 Bivio per Sestu, 09042 Monserrato, Italy \\ ${ }^{2}$ Department of Anesthesia and Intensive Care, Vita-Salute San Raffaele University, Via Olgettina 60, 20132 Milano, Italy \\ ${ }^{3}$ Department of Anesthesia and Intensive Care, Catholic University, Via Giuseppe Moscati 31, 00198 Roma, Italy \\ ${ }^{4}$ MSc Program "Cardiopulmonary Resuscitation", University of Athens, Medical School, Hellenic Society of \\ Cardiopulmonary Resuscitation, 75 Mikras Asias Street, 11527 Athens, Greece
}

Correspondence should be addressed to Andrea Pasquale Cossu; andreapcossu@yahoo.it

Received 8 May 2014; Accepted 28 July 2014; Published 1 September 2014

Academic Editor: Ahmed Abdel-Latif

Copyright (C) 2014 Andrea Pasquale Cossu et al. This is an open access article distributed under the Creative Commons Attribution License, which permits unrestricted use, distribution, and reproduction in any medium, provided the original work is properly cited.

\begin{abstract}
Objective. The latest European guidelines for the management of hemorrhagic shock suggest the use of vasopressors (norepinephrine) in order to restore an adequate mean arterial pressure when fluid resuscitation therapy fails to restore blood pressure. The administration of arginine vasopressin (AVP), or its analogue terlipressin, has been proposed as an alternative treatment in the early stages of hypovolemic shock. Design. A meta-analysis of randomized controlled animal trials. Participants. A total of 433 animals from 15 studies were included. Interventions. The ability of AVP and terlipressin to reduce mortality when compared with fluid resuscitation therapy, other vasopressors (norepinephrine or epinephrine), or placebo was investigated. Measurements and Main Results. Pooled estimates showed that AVP and terlipressin consistently and significantly improve survival in hemorrhagic shock (mortality: 26/174 (15\%) in the AVP group versus 164/259 (63\%) in the control arms; OR = 0.09; $95 \%$ CI 0.05 to 0.15 ; $P$ for effect $<0.001 ; P$ for heterogeneity $\left.=0.30 ; I_{2}=14 \%\right)$. Conclusions. Results suggest that AVP and terlipressin improve survival in the early phases of animal models of hemorrhagic shock. Vasopressin seems to be more effective than all other treatments, including other vasopressor drugs. These results need to be confirmed by human clinical trials.
\end{abstract}

\section{Introduction}

Trauma is the principal cause of death for people under 35 years of age, with more than 5 million injury-related deaths every year in the world. Approximately $30 \%$ of these deaths can be attributed to hemorrhagic shock $[1,2]$. Untreated prehospital hemorrhagic shock is one of the leading causes of cardiac arrest [3, 4]. Appropriate management and treatment are necessary to prevent adverse events and outcomes [5-7]. The early phase of hemorrhagic shock is characterized by a vasoconstrictive response and if the shock is left untreated it can lead to vasodilation that does not respond to conventional resuscitation strategies $[8,9]$. Prehospital hemorrhagic shock treatment should be focused on maintaining adequate mean arterial pressure (MAP) along with organ perfusion up until arrival at the hospital $[10,11]$.

Small volume resuscitation with colloids or hyperoncotic fluids may be useful during early phases of uncontrolled bleeding [12-14]. Recent international guidelines suggest that vasopressors may also be required to maintain tissue perfusion where fluid resuscitation itself does not achieve the expected goal [15].

Arginine vasopressin (AVP) is an endogenous neurohypophysial hormone with an antidiuretic function. The 
most important AVP release stimulus is the plasma osmolality variation followed by blood pressure variations [1618]. AVP also suppresses nitric oxide (NO) production [19]. The AVP release may also be suppressed by increased levels of norepinephrine and the increased release of NO from vascular endothelium of the posterior pituitary gland $[20,21]$. Terlipressin is a long-acting synthetic analogue of AVP, proposed in the septic shock management as a rescue therapy, when adequate MAP values are difficult to reach with standard therapy. It is characterized by a longer duration of action and a higher selectivity on the $V_{1}$ receptors that limits the edemigenous effect mediated by the $V_{2}$ receptors differently from what its native counterpart does [22]. AVP and terlipressin can be both used with the aim of reaching the desired MAP target or reducing the norepinephrine dosage $[23,24]$.

In animal models in which severe uncontrolled blood loss has been induced, the administration of AVP has shown improvement in survival, neurologic outcome, and enhanced hemodynamic performance [25-27]. During the irreversible phase of hemorrhagic shock, unresponsive to fluids and catecholamines administration, AVP can mediate peripheral vasoconstriction through $\mathrm{V}_{1}$ receptors [13, 28, 29]. AVP works primarily on arterioles in extracerebral tissues, with less constriction action on coronary and renal vessels with potential vasodilatory effect on cerebral and pulmonary flow [30]. Recent animal studies have shown that AVP treatment can achieve hemodynamic optimization during prehospital hemorrhagic shock, while fluids and catecholamines showed neither improvement of hemodynamic parameters nor survival $[1,31,32]$.

AVP use is associated with some adverse effects such as ischemic complications especially in cardiac, splanchnic, and skin circulation [33]. The decreased gut perfusion may determine tissue necrosis with subsequent translocation of bacteria that promotes the development of sepsis in the postresuscitation phase [34]. The increased expression of the $\mathrm{V}_{1}$ receptor subtype in trauma brain injury might promote the development of cerebral edema $[8,35]$.

To evaluate the impact on survival of $\mathrm{V}_{1}$ receptor agonists in hypovolemic refractory shock, we conducted a systematic review and meta-analysis of data pooled from existing trials comparing AVP or terlipressin and conventional shock management in mammals.

\section{Materials and Methods}

2.1. Search Strategy. All randomized animal trials using AVP or terlipressin in hypovolemic shock were identified. Relevant studies were independently searched by two trained investigators in Google Scholar and PubMed (updated November 4, 2013). The full PubMed search strategy, including keywords AVP, arginine vasopressin, terlipressin, and hemorrhagic and hypovolemic shock, was developed according to BiondiZoccai et al. and is available in the Appendix [36].

2.2. Study Selection. References obtained from databases and literature searches were first examined independently at the title/abstract level by two investigators, with divergences resolved by consensus and then, if potentially pertinent, retrieved as a complete article.

Inclusion criteria for potentially relevant studies were random allocation to treatment; animal experimental design; comparison of AVP or terlipressin (with or without fluid administration) versus placebo or fluids or catecholamines or both fluids plus catecholamines. Exclusion criteria were duplicate publications, human trials, and studies with no data on survival. Two investigators selected studies for the final analysis by independently assessing compliance to the selection criteria. Divergences from the selection criteria were resolved by consensus.

2.3. Data Abstraction and Study Characteristics. Two investigators independently extracted data on the study design, experimental setting, dosages of AVP or terlipressin, and experimental duration, with divergences resolved by consensus. If the required data could not be retrieved from the published report, at least two separate attempts to contact the original authors were made.

The primary end-point was mortality at the longest available follow-up. In addition, we performed further subanalysis comparing animals treated with AVP (or terlipressin) with those treated, respectively, with placebo, fluid resuscitation, and other vasoconstrictive drugs.

2.4. Data Analysis and Synthesis. Computations were performed with RevMan 4.2 [35]. Binary outcomes from individual studies were analyzed to compute individual odds ratios (ORs) with pertinent 95\% confidence intervals (CIs), and a pooled summary effect estimate was calculated by means of the Mantel-Haenszel method and the fixed effect model in case of low statistical inconsistency $\left(I^{2}<25 \%\right)$ or the random-effect model in case of moderate or high statistical inconsistency $\left(I^{2}>25 \%\right)$ [37]. Statistical heterogeneity and inconsistency were measured using Cochran $Q$ tests and $I^{2}$ (by Higgins and Thompson), respectively [38]. Statistical significance was set at 2-tailed 0.05 for hypothesis testing and at 0.10 for heterogeneity testing. According to Higgins et al., the $I^{2}$ values around 25\%,50\%, and 75\% were considered to represent, respectively, low, moderate, and severe statistical inconsistency [38].

The risk of publication bias was assessed by visual inspection of the funnel plot for mortality. Sensitivity analyses were performed by sequentially removing each study and reanalysing the remaining dataset (producing a new analysis for each study removed) and by analysing only data from studies with low risk of bias.

\section{Results}

3.1. Study Characteristics. Database searches, backwards snowballing, and contacts with experts yielded a total of 246 citations. After excluding nonpertinent titles or abstracts, 22 studies were retrieved in complete form and assessed according to the selection criteria (Figure 1). Seven studies 
were further excluded for the absence of survival data. Fifteen eligible trials were included in the final analysis.

The 15 included studies randomized 433 animals, 174 to AVP (14 trials) or terlipressin (one trial) and 259 to control (placebo, vasopressors, or fluid resuscitation). The included trials were conducted on pigs (12 studies) and on rats (three studies). All manuscripts were published in indexed journals. Detailed study characteristics are summarized in Table 1.

3.2. Quantitative Data Synthesis. The overall analysis showed that $\mathrm{AVP} /$ terlipressin were associated with a reduction in animal mortality (26/174 (15\%) in the AVP/terlipressin group versus $164 / 259(63 \%)$ in the control arms; OR $=0.09(95 \%$ CI $0.05-0.15)$; $P$ for effect $<0.001 ; P$ for heterogeneity $=$ $0.30 ; I^{2}=14 \%$ ) (Figure 2). When studies were grouped to either fluid resuscitation, placebo, norepinephrine, or other vasoconstrictive drugs as a comparator, administration of AVP/terlipressin was still associated with a reduction in mortality. (see Supplementary Figures 6(b)-6(e) available online at http://dx.doi.org/10.1155/2014/421291).

Visual inspection of funnel plot identified an asymmetrical shape, suggesting the presence of publication bias (Figure 3). Sensitivity analyses performed by sequentially removing each study and reanalysing the remaining dataset (producing a new analysis for each study removed) did not lead to major changes in direction or magnitude of statistical findings. Sensitivity analyses carried out with studies with low risk of bias (eliminating the studies responsible for the asymmetry of the funnel plot) confirmed the overall results of our work showing a reduction in mortality in AVP/terlipressin animals versus controls (OR $=0.13(95 \%$ CI $0.08-0.24)$; $P$ for effect $<0.001, P$ for heterogeneity $0.99, I^{2}=0 \%$ with 10 studies and 329 animals included) (Figures 4 and 5). Data of mortality are summarized in Table 2 .

In the majority of the studies included in this metaanalysis, AVP has been administered with an initial bolus followed by continuous infusion. Bolus doses ranged from $0.1 \mathrm{U} / \mathrm{kg}$ to $0.4 \mathrm{U} / \mathrm{kg}$ while continuous infusion dosages ranged from $0.04 \mathrm{U} / \mathrm{kg} / \mathrm{min}$ to $0.08 \mathrm{U} / \mathrm{kg} / \mathrm{min}$. Other studies report AVP infusion dosages in $\mathrm{U} / \mathrm{kg} / \mathrm{h}$ that range from 0.1 [21] to $2 \mathrm{U} / \mathrm{kg} / \mathrm{h}[39,40]$. In the study of Bayram et al., terlipressin was administered at the dose of $50 \mathrm{mcg} / \mathrm{kg}$ [3].

\section{Discussion}

The most important finding of this meta-analysis is that the use of AVP in the hypovolemic shock increases survival in animal studies. All studies included were randomized (AVP or terlipressin versus placebo, other vasopressors or fluid administration), were conducted on animal models (pig and rats), and were published in peer-reviewed journals.

The use of vasopressors in hypovolemic shock might contradict the conventional knowledge of how to treat this condition. Nevertheless their use in late phases of hemorrhagic shock is a common practice. Vasopressors have recently been suggested in the European guidelines for the management of hemorrhagic shock in order to maintain an adequate mean arterial pressure when fluid therapy gives no positive results $[15,41]$. Guidelines recommend the use of norepinephrine as the vasopressor of choice, whilst the use of terlipressin or AVP is not mentioned.

The use of AVP and its synthetic analog terlipressin has received significant attention in clinical practice, especially in septic shock and cardiac arrest [43-46]. AVP was discovered in 1895 from the extract of the posterior pituitary gland and named after its vasoconstrictive properties $[16,42]$.

Landry et al. reported, for the first time, the successful administration of exogenous AVP in patients with septic shock [43]. Russell et al. compared the use of AVP versus norepinephrine in patients with septic shock in the "Vasopressin and Septic Shock Trial."

In 779 patients the adverse effects were similar in both groups, with no differences in 28-day mortality and major organ dysfunction [44]. Another potential use of AVP is in the pharmacological treatment of cardiac arrest $[45,46]$. AVP followed by epinephrine may be more effective than epinephrine alone in the treatment of refractory cardiac arrest, especially in patients with asystole [29].

In recent years, several animal studies have shown that the administration of AVP in patients with uncontrolled hemorrhagic shock is a promising treatment [10]. Our systematic analysis of literature has evaluated several clinical studies on animals. Morales et al. were the first ones to study the effects of the administration of different doses of AVP (from 1 to $4 \mathrm{mU} / \mathrm{kg}$ ) in seven dogs undergoing prolonged hemorrhagic shock and concluded that AVP is an effective agent in the irreversible phase of hemorrhagic shock unresponsive to volume replacement and catecholamines [28].

For a long time the use of vasopressors in hemorrhagic shock was considered a debatable topic. During the early phases of hemorrhagic shock arterial pressure is maintained as adequate through the activation of compensatory vasoconstrictive mechanisms guaranteed by the sympathetic system that produces a venous and arterial compensatory vasoconstriction [41].

When blood loss is abundant and this mechanism is no longer efficient to maintain an adequate organ perfusion, the sympathetic system becomes inhibited with subsequent reduction of peripheral resistance and bradycardia. Hemorrhagic shock is also responsible for an abnormal vascular bed reaction mediated by nitric oxide that reduces the response to endogenous and exogenous norephineprine [47]. The trauma and organ damage developing from the shockinduced hypoperfusion bring about the activation of the inflammatory cascade with subsequent vasoplegia $[48,49]$.

The use of vasopressors may be helpful in these cases. In their retrospective study Plurad et al. determined that an early vasopressor exposure after a critical injury is independently associated with an increased mortality rate and this is not related to the volemic status where hypovolemic patients are those with values of central venous pressure $\leq 8 \mathrm{mmHg}$. In this retrospective study, vasopressor exposure was associated with death independent of injury severity. Vasopressortreated patients had lower arterial pressure, required more fluids and transfusions, and had a higher serum creatine [50]. 


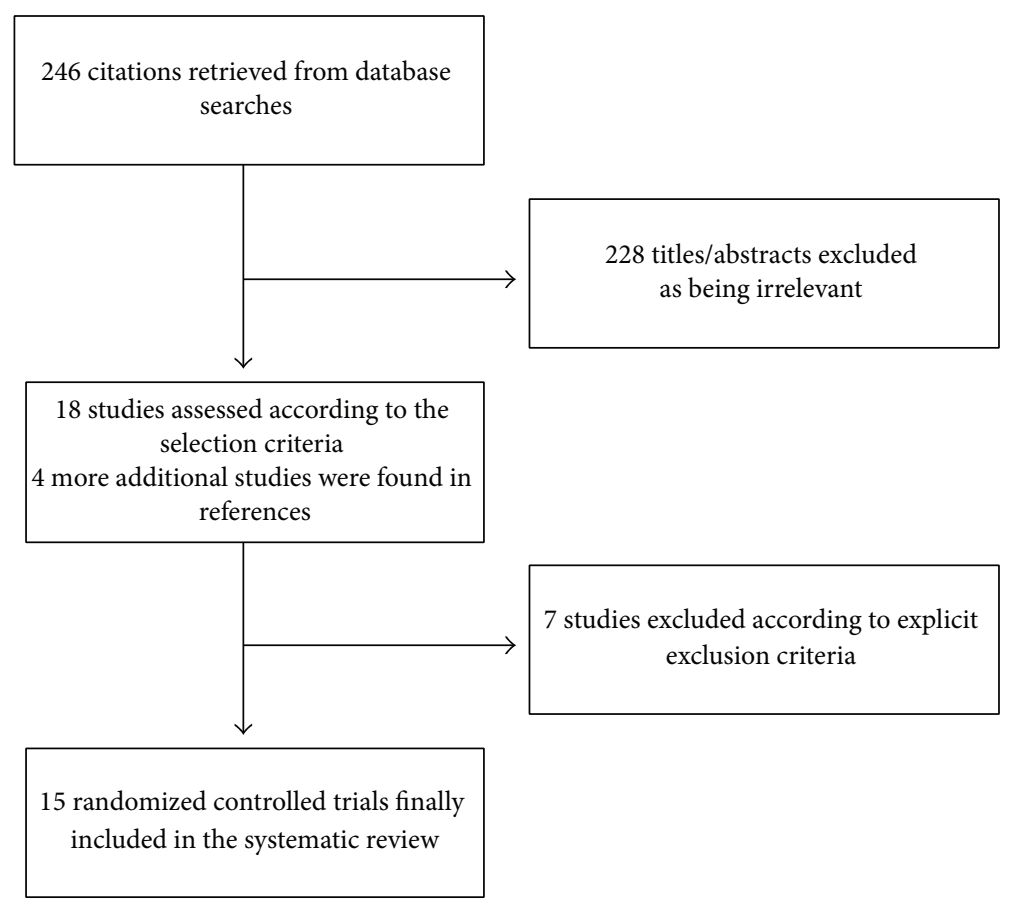

FIGURE 1: Flow diagram of the systematic review process.

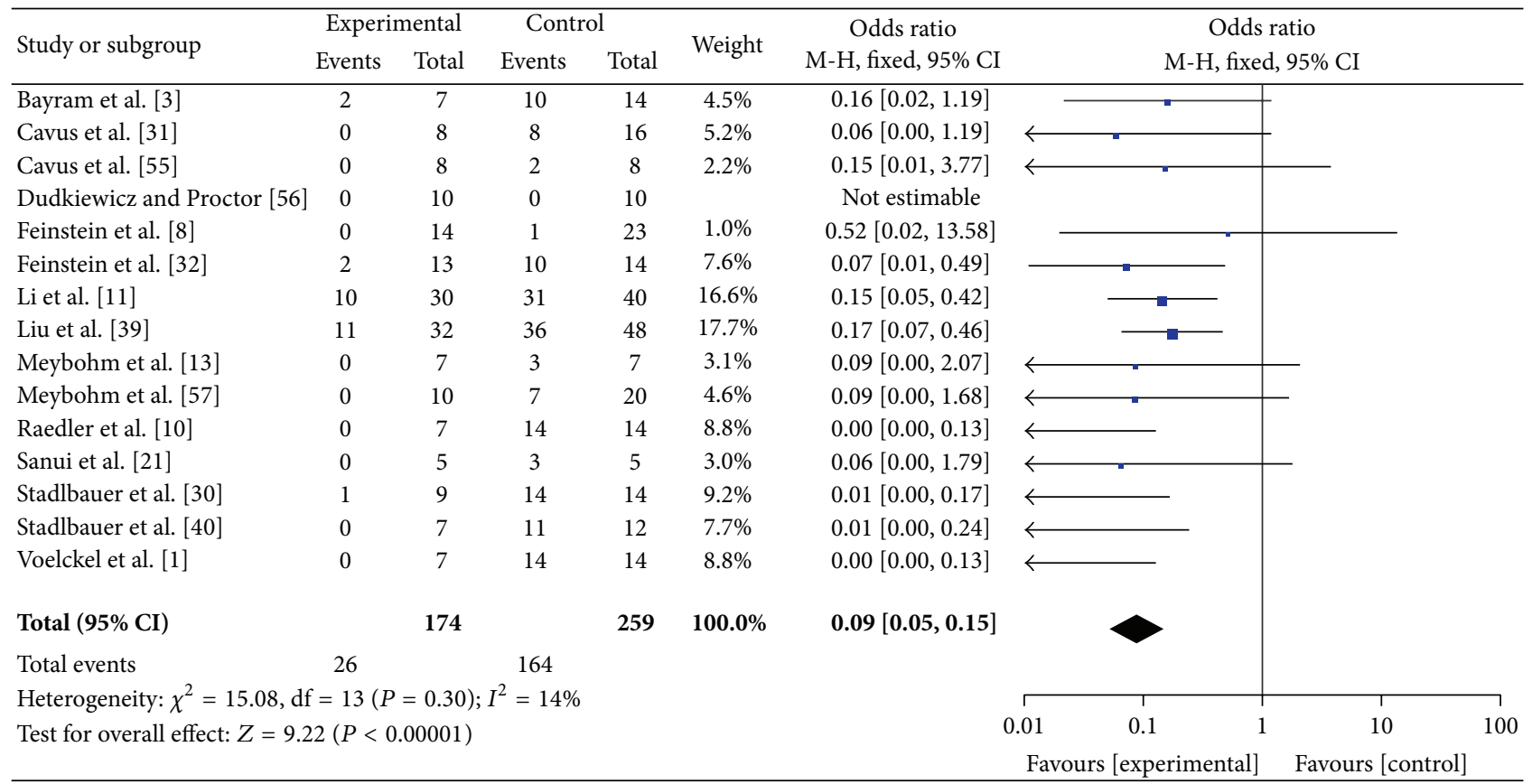

FIGURE 2: AVP or terlipressin versus all other strategies (fluid resuscitation, vasoconstrictors, and placebo).

However the update of the European guidelines has recently considered the use of norepinephrine for irreversible hemorrhagic shock. There are several human case reports that have supported the use of AVP as an optimizing measure capable of supporting arterial pressure during the triage of trauma victims $[27,51]$.
At present, a multicenter, randomized controlled trial (Vasopressin in Traumatic Hemorrhagic Shock-VITRIS study) is being organized in Europe to evaluate the effects of AVP in prehospital management of hemorrhagic shock [52]. Unfortunately, as of now, we only have the results of retrospective studies on humans. Collier et al. conducted 
TABLE 1: Studies included in the meta-analysis.

\begin{tabular}{|c|c|c|c|c|c|c|}
\hline 1st author & Journal & Year & Number of AVP (V) or terlipressin (T) & Number of Controls & Control & Animal \\
\hline Bayram [3] & Am J Emerg Med & 2012 & $7(\mathrm{~T})$ & 14 & $\begin{array}{c}\text { Placebo (7); } \\
\text { Ringer lactate (7) }\end{array}$ & Rats \\
\hline Cavus [31] & Resuscitation & 2009 & $8(\mathrm{~V})$ & 8 & Fluid resuscitation $(8)$ & Pigs \\
\hline Cavus [55] & Resuscitation & 2010 & $8(\mathrm{~V})$ & 16 & $\begin{array}{l}\text { Fluid resuscitation (8); } \\
\text { noradrenaline + HS (8) }\end{array}$ & Pigs \\
\hline Dudkiewicz [56] & Crit Care Med & 2008 & $10(\mathrm{~V})$ & 10 & Phenylephrine (10) & Pigs \\
\hline Feinstein $[8]$ & J Am Coll Surg & 2005 & $14(\mathrm{~V})$ & 23 & $\begin{array}{c}\text { Crystalloid (9); } \\
\text { phenylephrine (5); } \\
\text { crystalloid + } \\
\text { phenylephrine (9) }\end{array}$ & Pigs \\
\hline Feinstein [32] & J Trauma & 2005 & $8(\mathrm{~V})$ & 9 & NS (9) & Pigs \\
\hline Li [11] & J Surg Res & 2011 & $30(\mathrm{~V})$ & 40 & $\begin{array}{c}\text { Placebo (10); Ringer } \\
\text { lactate (10); whole blood } \\
\text { (10); NE (10) }\end{array}$ & Rats \\
\hline Liu [39] & Shock & 2013 & $32(\mathrm{~V})$ & 48 & $\begin{array}{c}\text { Hypotensive } \\
\text { resuscitation (16); } \\
\text { Ringer lactate (16); NE } \\
(16)\end{array}$ & Rats \\
\hline Meybohm [13] & J Trauma & 2007 & $7(\mathrm{~V})$ & 7 & HHS + NE (7) & Pigs \\
\hline Meybohm [57] & Resuscitation & 2008 & $10(\mathrm{~V})$ & 20 & $\begin{array}{c}\text { Fluid (10); HHS + NS } \\
(10)\end{array}$ & Pigs \\
\hline Raedler [10] & Anesth Analg & 2004 & $7(\mathrm{~V})$ & 14 & $\begin{array}{l}\text { Saline placebo (7); } \\
\text { fluid resuscitation (7) }\end{array}$ & Pigs \\
\hline Sanui [21] & Crit Care Med & 2006 & $5(\mathrm{~V})$ & 5 & Placebo (5) & Pigs \\
\hline Stadlbauer [30] & Anesthesiology & 2003 & $9(\mathrm{~V})$ & 14 & $\begin{array}{l}\text { Saline placebo (7); } \\
\text { fluid resuscitation (7) }\end{array}$ & Pigs \\
\hline Stadlbauer [40] & Crit Care & 2007 & $7(\mathrm{~V})$ & 12 & $\begin{array}{l}\text { Saline placebo (5); } \\
\text { fluid resuscitation (7) }\end{array}$ & Pigs \\
\hline Voelckel [1] & Crit Care Med & 2003 & $7(\mathrm{~V})$ & 14 & $\begin{array}{l}\text { Epinephrine (7); } \\
\text { saline placebo (7) }\end{array}$ & Pigs \\
\hline
\end{tabular}

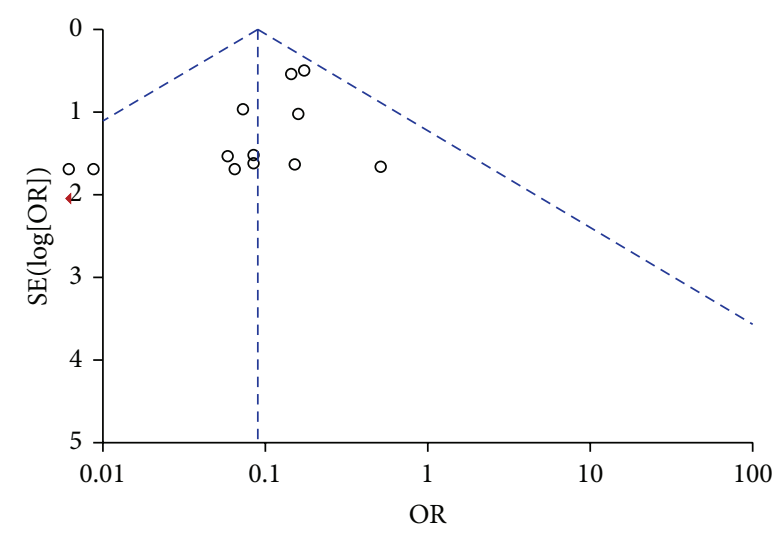

FIGURE 3: Funnel plot of comparison of AVP or terlipressin versus all other strategies (fluid resuscitation, vasoconstrictors, and placebo).

a retrospective cohort analysis of trauma patients requiring vasopressors within 72 hours of admission. They observed higher mortality (51\% versus $41 \%$ ) in patients treated with
AVP concluding that its administration is associated with increased mortality in trauma patients with refractory hypotension [53]. However patients treated with AVP in this study have higher values of Trauma-Injury Severity Score (TRISS) and initial lactate levels. Arterial blood pressure values of these two groups are not reported. Grmec et al. performed a prehospital prospective cohort study to assess the influence of treatment with AVP and hydroxyethyl starch solution (HHS) on outcome in resuscitated blunt trauma patients with pulseless electrical activity (PEA) cardiac arrest. Thirty-one patients were studied concluding that victims of severe blunt trauma with PEA should be initially treated with AVP in combination with HHS for volume resuscitation followed by standard resuscitation therapy and other procedures when needed [54].

Studies conducted on animals have several limitations. Survival times measured in the experiments are different. The median value is 15.5 hours and the median is 1.5 hours. Few studies keep observing animals after six hours [11, 30]. Those studies are performed with different protocols in settings 


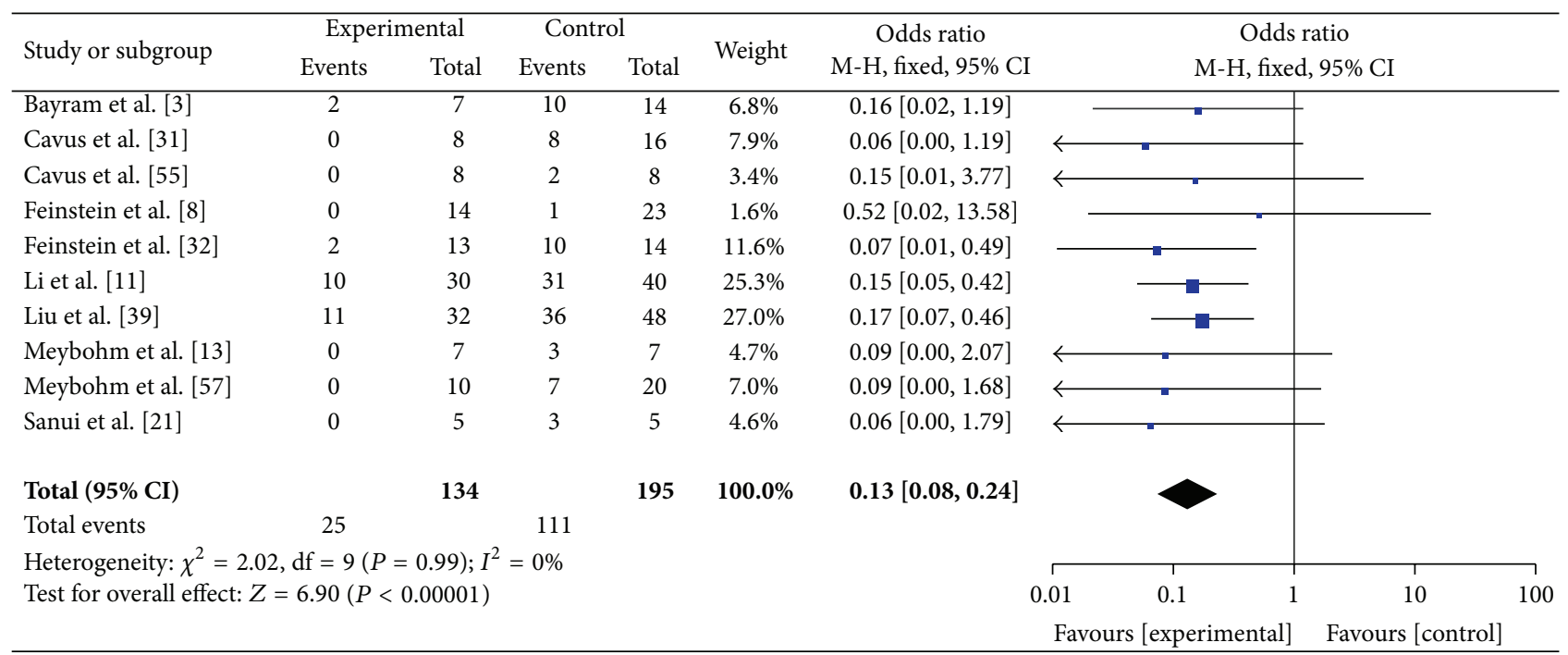

FIGURE 4: Forest plot of comparison of AVP or terlipressin versus all other strategies including studies with low risk of bias.

TABLE 2: Results for mortality.

\begin{tabular}{|c|c|c|c|c|c|c|c|c|}
\hline Outcome & $\begin{array}{c}\text { Number of } \\
\text { included } \\
\text { trials }\end{array}$ & $\begin{array}{l}\text { AVP/terlipressin } \\
\text { animals }\end{array}$ & $\begin{array}{l}\text { Control } \\
\text { animals }\end{array}$ & OR & $95 \%$ CI & $P$ for effect & $P$ for heterogeneity & $I^{2}(\%)$ \\
\hline Overall trials & 15 & 174 & 259 & 0.09 & $0.05-0.15$ & $<0.001$ & 0.30 & 14 \\
\hline Mortality & & $15 \%$ & $63 \%$ & & & & & \\
\hline Placebo as comparator drug & 7 & 72 & 48 & 0.03 & $0.01-0.09$ & $<0.001$ & 0.57 & 0 \\
\hline Mortality & & $18 \%$ & $92 \%$ & & & & & \\
\hline $\begin{array}{l}\text { Fluid resuscitation as } \\
\text { comparator drug }\end{array}$ & 11 & 114 & 117 & 0.08 & $0.04-0.15$ & $<0.001$ & 0.75 & 0 \\
\hline Mortality & & $18 \%$ & $67 \%$ & & & & & \\
\hline $\begin{array}{l}\text { Vasopressors (NE or } \\
\text { epinephrine) as comparator } \\
\text { drug }\end{array}$ & 7 & 88 & 87 & 0.18 & $0.08-0.44$ & $<0.001$ & 0.96 & 0 \\
\hline Mortality & & $18 \%$ & $39 \%$ & & & & & \\
\hline $\mathrm{NE}$ as comparator drug & 4 & 54 & 53 & 0.16 & $0.06-0.45$ & $<0.001$ & 0.97 & 0 \\
\hline Mortality & & $20 \%$ & $47 \%$ & & & & & \\
\hline $\begin{array}{l}\text { Sensitivity analysis } \\
\text { (including only low risk of } \\
\text { bias studies) }\end{array}$ & 10 & 134 & 195 & 0.13 & $0.08-0.24$ & $<0.001$ & 0.99 & 0 \\
\hline Mortality & & $18 \%$ & $57 \%$ & & & & & \\
\hline
\end{tabular}

varying from head trauma $[55,56]$, thoracic trauma, and abdominal trauma [40] or after severe hepatic lesions [57].

Dosages used in animal trials are higher than dosages used in human studies. Humans have been successfully treated with AVP infusion of $2-4 \mathrm{U} / \mathrm{h}$ in vasodilatory shock $[58,59]$ and $10-20$ UI boluses in patients with upper intestinal bleeding [60]. Most of the studies favorably estimate the impact of AVP to handle hemodynamic and improve survival. However it is recommended not to underestimate the possible adverse effects that might derive from the use of AVP since its use is only indicated in irreversible shock no longer treatable with fluid resuscitation alone. Vasopressin could be considered as a possible pharmacologic adjunct in patients with shock refractory to the administration of fluids and catecholamines but the use of AVP alone cannot replace the use of fluids [61]. The AVP, as well as other vasopressors, seems to be beneficial only when administered in association with fluids $[62,63]$.

\section{Conclusions}

Data acquired from our meta-analysis suggest strong scientific evidence for the efficacy of AVP for the early treatment of hemorrhagic shock in animal models. AVP has shown to be more effective than all other treatments, including other vasopressors drugs. We are awaiting the results of the VITRIS 


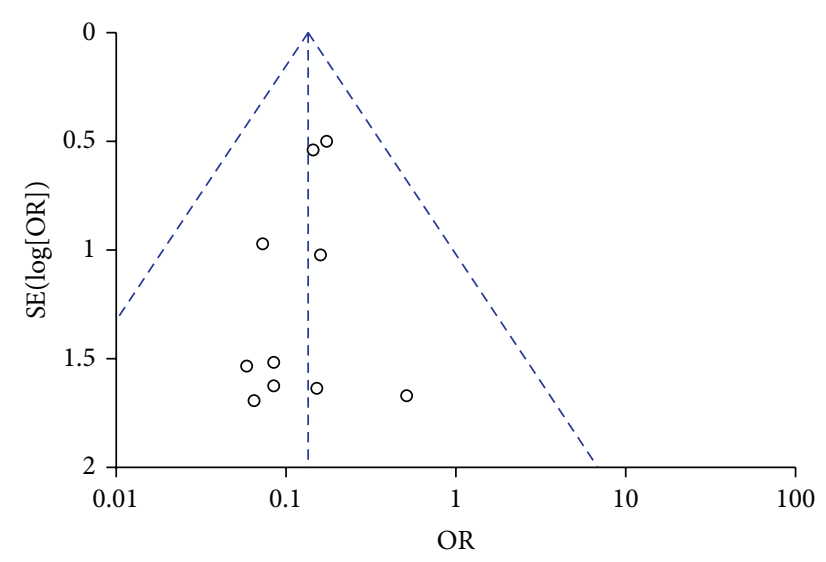

FIGURE 5: Funnel plot of comparison of AVP or terlipressin versus all other strategies including studies with low risk of bias.

[50] study to confirm in humans the results obtained in animal studies.

\section{Methodological Limitations}

The purposes, designs, and conduct are different between systematic review and meta-analysis of preclinical and clinical studies. Clinical reviews are intrinsically confirmatory and the aim of a Cochrane review is to provide evidence to allow practitioners and patients to make informed decisions about the delivery of health-care. Animal studies are meant to be exploratory and do not lead to definitive conclusions directly applicable to humans [64].

The results shown should be interpreted with caution. Animal studies are inherently heterogeneous, more than the typical clinical trials. Successfully translating findings to human diseases depends largely upon understanding the sources of heterogeneity and their impact on effect size [64]. The study is conducted without randomized controlled trials in humans, and our findings should only be considered as a hypothetical suggestion for further research, awaiting the results of randomized controlled human trials.

\section{Appendix}

("Vasopressin"[MeSH Terms] OR terlipressin[Text Word] OR "arginine vasopressin" [Text Word]) AND ("hemorrhagic shock" OR trauma) AND ((randomized controlled trial[pt] OR controlled clinical trial[pt] OR randomized controlled trials $[\mathrm{mh}] \mathrm{OR}$ random allocation $[\mathrm{mh}]$ OR doubleblind method $[\mathrm{mh}]$ OR single-blind method $[\mathrm{mh}]$ OR clinical trial[pt] OR clinical trials[mh] OR ("clinical trial" $[\mathrm{tw}] \mathrm{OR}$ ((singl $l^{*}[\mathrm{tw}]$ OR doubl*[tw] OR trebl*[tw] OR tripl $\left.{ }^{*}[\mathrm{tw}]\right)$ AND (mask* $\left.{ }^{*} \mathrm{tw}\right]$ OR blind[tw])) OR ("latin square" [tw]) OR placebos[mh] OR placebo*[tw] OR random* $\left.{ }^{*} \mathrm{tw}\right]$ OR research design[mh:noexp] OR comparative study[mh] OR evaluation studies[mh] OR follow-up studies[mh] OR prospective studies[mh] OR crossover studies[mh] OR control ${ }^{*}[\mathrm{tw}]$ OR prospective* $[\mathrm{tw}]$ OR volunteer $\left.{ }^{*}[\mathrm{tw}]\right)$ OR (animal[mh] OR human[mh]) NOT (comment[pt] OR editorial[pt] OR (meta-analysis[pt] NOT clinical trial[pt]) OR practiceguideline[pt] OR review[pt]))).

\section{Conflict of Interests}

The authors declare that there is no conflict of interests regarding the publication of this paper.

\section{Acknowledgment}

The authors are indebted to Toby Schwartzbarth for the revision of the paper.

\section{References}

[1] W. G. Voelckel, C. Raedler, V. Wenzel et al., "Arginine vasopressin, but not epinephrine, improves survival in uncontrolled hemorrhagic shock after liver trauma in pigs," Critical Care Medicine, vol. 31, no. 4, pp. 1286-1287, 2003.

[2] W. C. Shoemaker, A. B. Peitzman, R. Bellamy et al., "Resuscitation from severe hemorrhage," Critical Care Medicine, vol. 24, no. 2, pp. S12-S23, 1996.

[3] B. Bayram, N. Hocaoglu, R. Atilla, and S. Kalkan, "Effects of terlipressin in a rat model of severe uncontrolled hemorrhage via liver injury," The American Journal of Emergency Medicine, vol. 30, no. 7, pp. 1176-1182, 2012.

[4] H. P. Santry and H. B. Alam, "Fluid resuscitation: past, present, and the future," Shock, vol. 33, no. 3, pp. 229-241, 2010.

[5] A. T. W. Cheung, P. L. To, D. M. Chan et al., "Comparison of treatment modalities for hemorrhagic shock," Artificial Cells, Blood Substitutes, and Biotechnology, vol. 35, no. 2, pp. 173-190, 2007.

[6] K. H. Stadlbauer, H. G. Wagner-Berger, V. Wenzel et al., "Survival with full neurologic recovery after prolonged cardiopulmonary resuscitation with a combination of vasopressin and epinephrine in pigs," Anesthesia and Analgesia, vol. 96, no. 6, pp. 1743-1749, 2003.

[7] F. G. Bonanno, "Hemorrhagic shock: the "physiology approach"', Journal of Emergencies, Trauma and Shock, vol. 5, no. 4, pp. 285-295, 2012.

[8] A. J. Feinstein, M. B. Patel, M. Sanui, S. M. Cohn, M. Majetschak, and K. G. Proctor, "Resuscitation with pressors after traumatic brain injury," Journal of the American College of Surgeons, vol. 201, no. 4, pp. 536-545, 2005.

[9] Y. Fang, T. Li, X. Fan, Y. Zhu, and L. Liu, "Beneficial effects of activation of PKC on hemorrhagic shock in rats," The Journal of Trauma, Injury, Infection and Critical Care, vol. 68, no. 4, pp. 865-873, 2010.

[10] C. Raedler, W. G. Voelckel, V. Wenzel et al., "Treatment of uncontrolled hemorrhagic shock after liver trauma: fatal effects of fluid resuscitation versus improved outcome after vasopressin," Anesthesia and Analgesia, vol. 98, no. 6, pp. 17591766, 2004.

[11] T. Li, Y. Fang, Y. Zhu et al., "A small dose of arginine vasopressin in combination with norepinephrine is a good early treatment for uncontrolled hemorrhagic shock after hemostasis," Journal of Surgical Research, vol. 169, no. 1, pp. 76-84, 2011.

[12] W. H. Bickell, M. J. Wall Jr., P. E. Pepe et al., "Immediate versus delayed fluid resuscitation for hypotensive patients with penetrating torso injuries," The New England Journal of Medicine, vol. 331, no. 17, pp. 1105-1109, 1994. 
[13] P. Meybohm, E. Cavus, B. Bein et al., "Small volume resuscitation: arandomized controlled trial with either norepinephrine or vasopressin during severe hemorrhage," Journal of Trauma: Injury Infection \& Critical Care, vol. 62, no. 3, pp. 640-646, 2007.

[14] W. G. Voelckel, V. A. Convertino, K. G. Lurie et al., "Vasopressin for hemorrhagic shock management: Revisiting the potential value in civilian and combat casualty care," Journal of Trauma, vol. 69, no. 1, pp. S69-S74, 2010.

[15] D. R. Spahn, B. Bouillon, V. Cerny et al., "Management of bleeding and coagulopathy following major trauma: an updated European guideline," Critical Care, vol. 17, no. 2, article R76, 2013.

[16] N. F. Holt and K. L. Haspel, "Vasopressin: a Review of Therapeutic Applications," Journal of Cardiothoracic and Vascular Anesthesia, vol. 24, no. 2, pp. 330-347, 2010.

[17] L. Bankir, "Antidiuretic action of vasopressin: quantitative aspects and interaction between V1a and V2 receptor-mediated effects," Cardiovascular Research, vol. 51, no. 3, pp. 372-390, 2001.

[18] J.-L. Vincent and F. Su, "Physiology and pathophysiology of the vasopressinergic system," Best Practice and Research: Clinical Anaesthesiology, vol. 22, no. 2, pp. 243-252, 2008.

[19] R. Moreau, E. Barrière, K. A. Tazi et al., "Terlipressin inhibits in vivo aortic iNOS expression induced by lipopolysaccharide in rats with biliary cirrhosis," Hepatology, vol. 36, no. 5, pp. 10701078, 2002.

[20] V. Wenzel and K. H. Lindner, "Employing vasopressin during cardiopulmonary resuscitation and vasodilatory shock as a lifesaving vasopressor," Cardiovascular Research, vol. 51, no. 3, pp. 529-541, 2001.

[21] M. Sanui, D. R. King, A. J. Feinstein, A. J. Varon, S. M. Conn, and K. G. Proctor, "Effects of arginine vasopressin during resuscitation from hemorrhagic hypotension after traumatic brain injury," Critical Care Medicine, vol. 34, no. 2, pp. 433-438, 2006.

[22] S. Rehberg, C. Ertmer, M. Lange et al., "Role of selective V2receptor-antagonism in septic shock: a randomized, controlled, experimental study," Critical Care, vol. 14, no. 6, article R200, 2010.

[23] R. P. Dellinger, M. M. Levy, A. Rhodes et al., "Surviving sepsis campaign: international guidelines for management of severe sepsis and septic shock: 2012," vol. 41, no. 2, pp. 580-637, 2013.

[24] A. Delmas, M. Leone, S. Rousseau, J. Albanèse, and C. Martin, "Clinical review: vasopressin and terlipressin in septic shock patients," Critical Care, vol. 9, no. 2, pp. 212-222, 2005.

[25] K. B. Johnson, F. J. Pearce, N. Jeffreys, S. W. McJames, and M. Cluff, "Impact of Vasopressin on Hemodynamic and Metabolic Function in the Decompensatory Phase of Hemorrhagic Shock," Journal of Cardiothoracic and Vascular Anesthesia, vol. 20, no. 2, pp. 167-172, 2006.

[26] W. G. Voelckel, K. G. Lurie, K. H. Lindner et al., "Vasopressin improves survival after cardiac arrest in hypovolemic shock," Anesthesia and Analgesia, vol. 91, no. 3, pp. 627-634, 2000.

[27] T. Haas, W. G. Voelckel, F. Wiedermann, V. Wenzel, and K. H. Lindner, "Successful resuscitation of a traumatic cardiac arrest victim in hemorrhagic shock with vasopressin: a case report and brief review of the literature." The Journal of Trauma, vol. 57, no. 1, pp. 177-179, 2004.

[28] D. Morales, J. Madigan, S. Cullinane et al., "Reversal by vasopressin of intractable hypotension in the late phase of hemorrhagic shock," Circulation, vol. 100, no. 3, pp. 226-229, 1999.
[29] V. Wenzel, A. C. Krismer, H. R. Arntz, H. Sitter, K. H. Stadlbauer, and K. H. Lindner, "A comparison of vasopressin and epinephrine for out-of-hospital cardiopulmonary resuscitation," The New England Journal of Medicine, vol. 350, no. 2, pp. 105-113, 2004.

[30] K. H. Stadlbauer, H. G. Wagner-Berger, C. Raedler et al., "Vasopressin, but not fluid resuscitation, enhances survival in a liver trauma model with uncontrolled and otherwise lethal hemorrhagic shock in pigs," Anesthesiology, vol. 98, no. 3, pp. 699-704, 2003.

[31] E. Cavus, P. Meybohm, V. Doerges et al., "Cerebral effects of three resuscitation protocols in uncontrolled haemorrhagic shock: a randomised controlled experimental study," Resuscitation, vol. 80, no. 5, pp. 567-572, 2009.

[32] A. J. Feinstein, S. M. Cohn, D. R. King et al., "Early vasopressin improves short-term survival after pulmonary contusion," Journal of Trauma-Injury, Infection and Critical Care, vol. 59, no. 4, pp. 876-883, 2005.

[33] M. W. Dünser, A. J. Mayr, A. Tür et al., "Ischemic skin lesions as a complication of continuous vasopressin infusion in catecholamine-resistant vasodilatory shock: Incidence and risk factors," Critical Care Medicine, vol. 31, no. 5, pp. 1394-1398, 2003.

[34] A. W. Prengel, K. H. Lindner, V. Wenzel, I. Tugtekin, and T. Anhäupl, "Splanchnic and renal blood flow after cardiopulmonary resuscitation with epinephrine and vasopressin in pigs," Resuscitation, vol. 38, no. 1, pp. 19-24, 1998.

[35] J. Szmydynger-Chodobska, I. Chung, E. Koźniewska et al., "Increased expression of vasopressin Vla receptors after traumatic brain injury," Journal of Neurotrauma, vol. 21, no. 8, pp. 1090-1102, 2004.

[36] G. G. L. Biondi-Zoccai, P. Agostoni, A. Abbate, L. Testa, F. Burzotta, and K. A. Robinson, "A simple hint to improve Robinson and Dickersin's highly sensitive PubMed search strategy for controlled clinical trials," International Journal of Epidemiology, vol. 34, no. 1, pp. 224-225, 2005.

[37] A. Zangrillo, G. G. L. Biondi-Zoccai, E. Frati et al., "Fenoldopam and acute renal failure in cardiac surgery: a meta-analysis of randomized placebo-controlled trials," Journal of Cardiothoracic and Vascular Anesthesia, vol. 26, no. 3, pp. 407-413, 2012.

[38] J. P. T. Higgins, S. G. Thompson, J. J. Deeks, and D. G. Altman, "Measuring inconsistency in meta-analyses," The British Medical Journal, vol. 327, no. 7414, pp. 557-560, 2003.

[39] L. Liu, K. Tian, M. Xue et al., "Small doses of arginine vasopressin in combination with norepinephrine "buy" time for definitive treatment for uncontrolled hemorrhagic shock in rats," Shock, vol. 40, no. 5, pp. 398-406, 2013.

[40] K. H. Stadlbauer, H. G. Wagner-Berger, A. C. Krismer et al., "Vasopressin improves survival in a porcine model of abdominal vascular injury," Critical Care, vol. 11, article R81, 2007.

[41] F. Beloncle, F. Meziani, N. Lerolle, P. Radermacher, and P. Asfar, "Does vasopressor therapy have an indication in hemorrhagic shock?” Annals of Intensive Care, vol. 3, no. 1, pp. 1-6, 2013.

[42] G. Oliver and E. Schaefer, "On the physiological action of extract of pituitary body and certain other glandular organs," Journal of Physiology, vol. 18, pp. 277-279, 1895.

[43] D. W. Landry, H. R. Levin, E. M. Gallant et al., "Vasopressin pressor hypersensitivity in vasodilatory septic shock," Critical Care Medicine, vol. 25, no. 8, pp. 1279-1282, 1997. 
[44] J. A. Russell, K. R. Walley, J. Singer et al., "Vasopressin versus norepinephrine infusion in patients with septic shock," The New England Journal of Medicine, vol. 358, no. 9, pp. 877-887, 2008.

[45] K. H. Lindner, T. Haak, A. Keller, U. Bothner, and K. G. Lurie, "Release of endogenous vasopressors during and after cardiopulmonary resuscitation," Heart, vol. 75, no. 2, pp. 145150, 1996.

[46] K. H. Lindner, H. U. Strohmenger, H. Ensinger, W. D. Hetzel, F. W. Ahnefeld, and M. Georgieff, "Stress hormone response during and after cardiopulmonary resuscitation," Anesthesiology, vol. 77, no. 4, pp. 662-668, 1992.

[47] C. Thiemermann, C. Szabó, J. A. Mitchell, and J. R. Vane, "Vascular hyporeactivity to vasoconstrictor agents and hemodynamic decompensation in hemorrhagic shock is mediated by nitric oxide," Proceedings of the National Academy of Sciences of the United States of America, vol. 90, no. 1, pp. 267-271, 1993.

[48] H. K. Eltzschig and P. Carmeliet, "Hypoxia and inflammation," The New England Journal of Medicine, vol. 364, no. 7, pp. 656665, 2011.

[49] N. Smail, A. Descorps Declère, J. Duranteau, B. Vigué, and K. Samii, "Left ventricular function after severe trauma," Intensive Care Medicine, vol. 22, no. 5, pp. 439-442, 1996.

[50] D. S. Plurad, P. Talving, L. Lam, K. Inaba, D. Green, and D. Demetriades, "Early vasopressor use in critical injury is associated with mortality independent from volume status," Journal of Trauma-Injury, Infection and Critical Care, vol. 71, no. 3, pp. 565-572, 2011.

[51] R. M. Sharma and R. Setlur, "Vasopressin in hemorrhagic shock," Anesthesia and Analgesia, vol. 101, no. 3, pp. 833-834, 2005.

[52] H. G. Lienhart, V. Wenzel, J. Braun et al., "Vasopressin for therapy of persistent traumatic hemorrhagic shock: the VITRIS study," Anaesthesist, vol. 56, no. 2, pp. 145-150, 2007.

[53] B. Collier, L. Dossett, M. Mann et al., "Vasopressin use is associated with death in acute trauma patients with shock," Journal of Critical Care, vol. 25, no. 1, pp. 173.e9-173.e14, 2010.

[54] S. Grmec, M. Strnad, D. Cander, and S. Mally, "A treatment protocol including vasopressin and hydroxyethyl starch solution is associated with increased rate of return of spontaneous circulation in blunt trauma patients with pulseless electrical activity," International Journal of Emergency Medicine, vol. 1, no. 4, pp. 311-316, 2008.

[55] E. Cavus, P. Meybohm, V. Doerges et al., "Effects of cerebral hypoperfusion on bispectral index: a randomised, controlled animal experiment during haemorrhagic shock," Resuscitation, vol. 81, no. 9, pp. 1183-1189, 2010.

[56] M. Dudkiewicz and K. G. Proctor, "Tissue oxygenation during management of cerebral perfusion pressure with phenylephrine or vasopressin," Critical Care Medicine, vol. 36, no. 9, pp. 26412650, 2008.

[57] P. Meybohm, E. Cavus, V. Dörges et al., "Release of protein S100B in haemorrhagic shock: effects of small volume resuscitation combined with arginine vasopressin," Resuscitation, vol. 76, no. 3, pp. 449-456, 2008.

[58] H. G. Lienhart, K. H. Lindner, and V. Wenzel, "Developing alternative strategies for the treatment of traumatic haemorrhagic shock," Current Opinion in Critical Care, vol. 14, no. 3, pp. 247253, 2008.

[59] M. W. Dünser, A. J. Mayr, H. Ulmer et al., "The effects of vasopressin on systemic hemodynamics in catecholamine-resistant septic and postcardiotomy shock: a retrospective analysis," Anesthesia and Analgesia, vol. 93, no. 1, pp. 7-13, 2001.
[60] M. W. Dünser, V. Wenzel, A. J. Mayr, and W. R. Hasibeder, "Management of vasodilatory shock: defining the role of arginine vasopressin," Drugs, vol. 63, no. 3, pp. 237-256, 2003.

[61] J. L. Sperry, J. P. Minei, H. L. Frankel et al., "Early use of vasopressors after injury: caution before constriction," Journal of Trauma, vol. 64, no. 1, pp. 9-14, 2008.

[62] F. Beloncle, F. Meziani, N. Lerolle, P. Radermacher, and P. Asfar, "Does vasopressor therapy have an indication in hemorrhagic shock?" Annals of Intensive Care, vol. 3, article 13, 2013.

[63] R. R. Rajani, C. G. Ball, D. V. Feliciano, and G. A. Vercruysse, "Vasopressin in hemorrhagic shock: review article," American Surgeon, vol. 75, no. 12, pp. 1207-1212, 2009.

[64] H. M. Vesterinen, E. S. Sena, K. J. Egan et al., "Meta-analysis of data from animal studies: a practical guide," Journal of Neuroscience Methods, vol. 221, no. 15, pp. 92-102, 2014. 


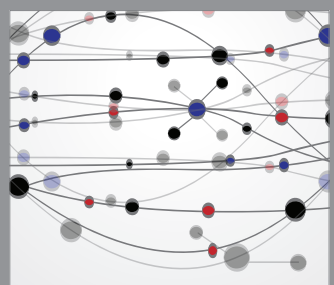

The Scientific World Journal
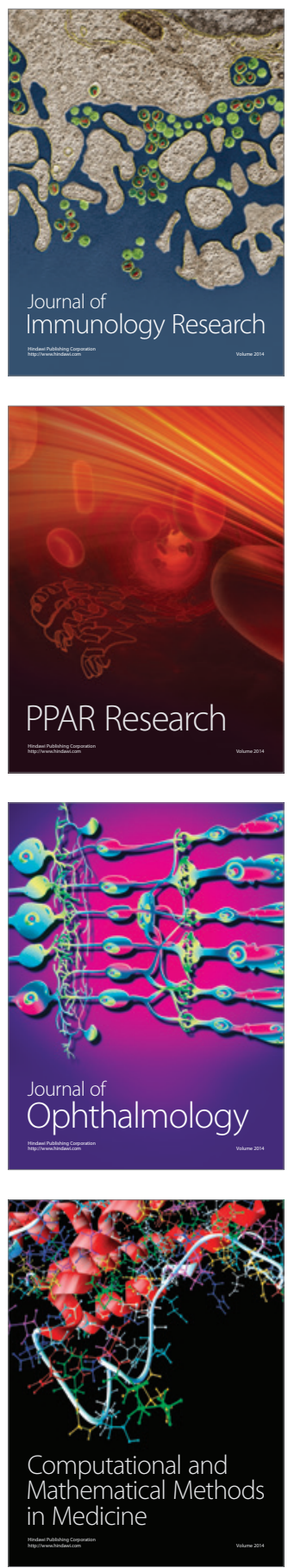

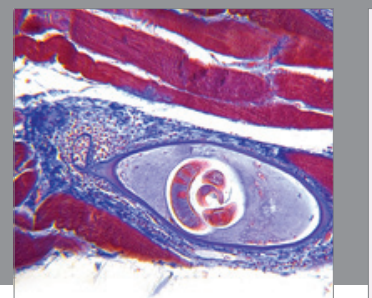

Gastroenterology

Research and Practice
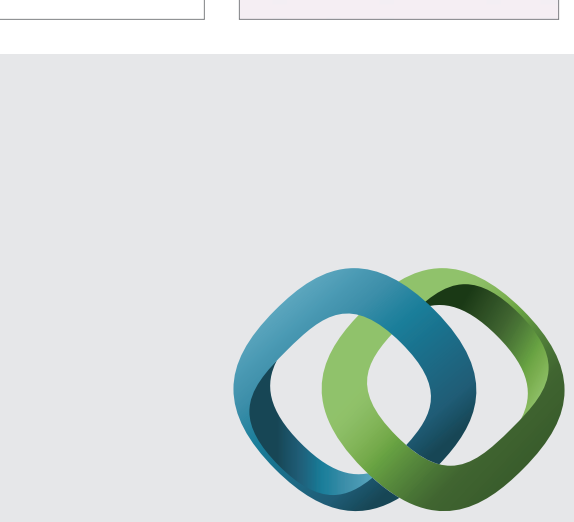

\section{Hindawi}

Submit your manuscripts at

http://www.hindawi.com
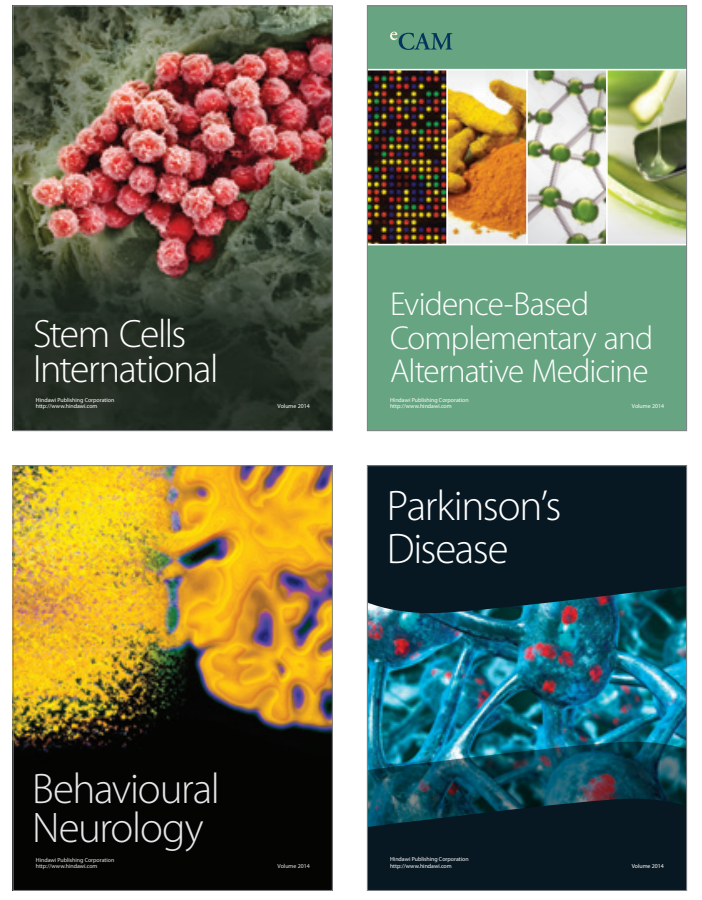
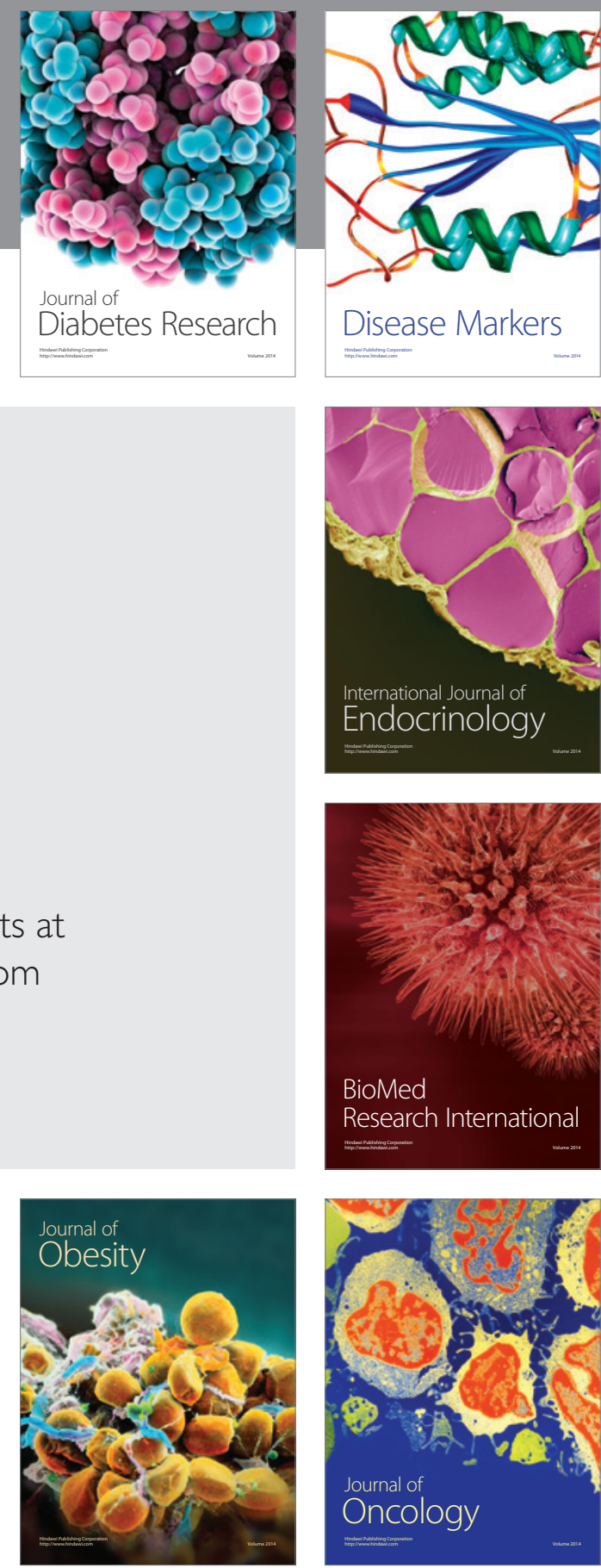

Disease Markers
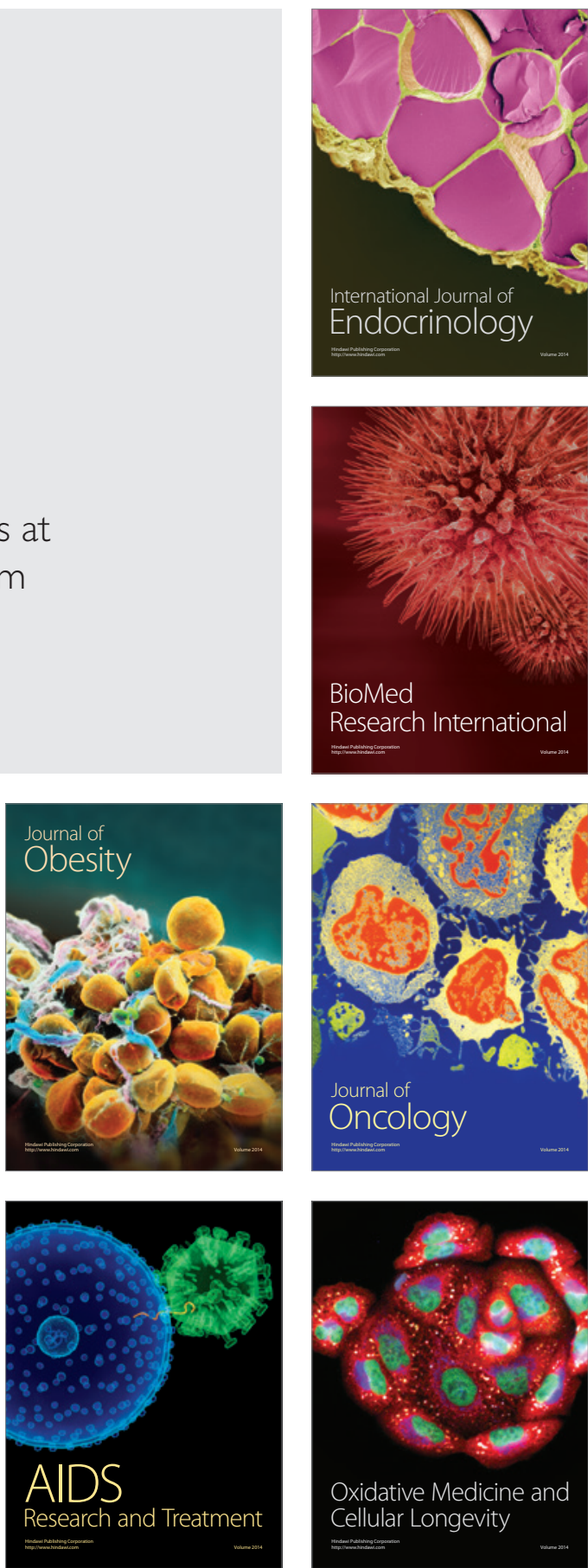